\title{
Türkiye'de Aphis craccivora Koch ve Brevicoryne brassicae (Linnaeus) (Hemiptera: Aphididae)'nin Yeni Konukçu Bitki Kaydı: Capsella rubella Reut. (Brassicaceae)
}

\author{
Şahin Kök ${ }^{1^{*}}$ İsmail Kasap ${ }^{1}$ Ersin Karabacak $^{2}$ \\ ${ }^{1}$ Çanakkale Onsekiz Mart Üniversitesi, Ziraat Fakültesi, Bitki Koruma Bölümü, Çanakkale \\ ${ }^{2}$ Çanakkale Onsekiz Mart Üniversitesi, Fen Edebiyat Fakültesi, Biyoloji Bölümü, Çanakkale \\ *Sorumlu yazar: sahinkok@gmail.com
}

Geliş Tarihi: 23.10.2019

Kabul Tarihi: 02.12.2019

\section{$\ddot{O} z$}

Afitler (Hemiptera: Aphididae) dünyada tarım ve tarımdışı alanlardaki bitkilerin ekonomik olarak en önemli herbivor zararlılarından birisidir. Afitler onların gıda kaynakları ve hayat döngüleri üzerinde hayati bir rol oynayan konukçu bitkiler ile yakın bir ilişki içerisindedir. Bu sebeple, Türkiye'nin tüm bölgelerinde farklı habitatlardaki afitler ve konukçu bitkilerinin kapsamlı bir şekilde belirlenmesi aralarındaki ilişkilerin net olarak anlaşılabilmesi açısından önemlidir. Bu çalışma ile Capsella rubella Reut. (Brassicaceae) bitkisi Türkiye'de ilk kez Çanakkale ilinden Aphis craccivora Koch and Brevicoryne brassicae (Linnaeus) afit türlerinin yeni konukçu bitkisi olarak tespit edilmiştir. Ayrıca sözkonusu afit türlerinin Türkiye'nin farklı bölgelerinde şimdiye kadar rapor edilen konukçu bitki türleri de verilmiştir. Bu sonuçlar hem Çanakkale ilinin hem de ülkemizin afitler ve konukçu bitkileri çeşitliliği bakımından önemli bir potansiyeli olduğunu göstermektedir.

Anahtar Kelimeler: Afit, yeni konukçu bitki, Capsella rubella, Çanakkale

\section{New Host Plant Record of Aphis craccivora Koch and Brevicoryne brassicae (Linnaeus) (Hemiptera: Aphididae) in Turkey: Capsella rubella Reut. (Brassicaceae) \\ Abstract}

Aphids (Hemiptera: Aphididae) are one of the most economically important herbivore pests of plants in the agricultural and non-agricultural areas worldwide. Aphids are closely associated with their host plants that play a vital role on their food sources and life cycles. For this reason, comprehensively determination of aphids and their host plants in different habitats in all regions of Turkey is important to be understood clearly the associations between them. With the study, Capsella rubella Reut. (Brassicaceae) was determined for the first time in Turkey as the new host plant species of Aphis craccivora Koch and Brevicoryne brassicae (Linnaeus) from Çanakkale Province. Also, it was given that the host plant species reported in different regions of Turkey of as mentioned aphids, so far. These results show that both Çanakkale and Turkey have the important potential in point of aphids and their host plants.

Keywords: Aphid, new host plant, Capsella rubella, Çanakkale

\section{Giriş}

Hemiptera takımı içerisinde yer alan Aphididae familyasına bağlı ve bitki paraziti olarak tanımlanan afitler farklı habitatlarda bulunan tek yıllık yabancı ot, ağaç ve çalı formundaki bitkiler ile süs bitkilerini konukçu olarak tercih etmektedir. Dünya'da tespit edilen 534 cins içerisindeki 5260'dan fazla afit türünün yaklaşı $\% 55$ 'inin yabancı ot ve çalımsı bitkiler ve $\% 40$ 'ının ise ağaç formundaki bitkiler üzerinde dağılım gösterdiği bilinmektedir. Afit türlerinin yaklaşık \%5'lik kısmının ise konukçu bitki deseni hakkında bilgiler bulunmamaktadır (Blackman ve Eastop, 2006). Günümüze kadar yürütülen çalışmalar sonucunda afitlerin çoğunluğunu çiçekli yabanc1 ot formundaki bitkilerin oluşturduğu 300'den fazla bitki familyasını konukçu bitki olarak seçtiği belirtilmektedir (Blackman ve Eastop, 2019).

Oldukça değiş̧ken bitki çeşitliliğine sahip olan afitlerin konukçu bitkileri ile sıkı bir ilişki içerisinde olduğu bilinmektedir (Hille Ris Lambers, 1979). Yapılan çalışmalar afitlerin konukçu bitkileri ile rastgele bir ilişkiye sahip olmadığını göstermektedir. Afitler bazı bitki familyalarını oldukça yaygın tercih etmesine rağmen bazı bitki familyaları üzerinde tespit edilen afit türlerinin 
sayısı oldukça sınırlı olmaktadır. Yapılan çalışmalarda Apiaceae ve Asteraceae familyalarına ait bitkiler üzerinde 600 , Coniferae bitkileri üzerinde 350 ve çoğunluğunu ağaç ve çalımsı bitkilerin oluşturduğu Rosaceae familyası üzerinde 300'den fazla afit türü (Blackman ve Eastop, 2006) tespit edilmesine rağmen Cactaceae, Euphorbiaceae, Lauraceae, Moraceae, Myrtaceae ve Orchidaceae gibi fazla sayıda bitki türü içeren familyalar üzerinde ise oldukça az sayıda afit türü kayıt edilmiştir (Dixon, 1998). Afitler ağılıklı olarak ılıman kuşak iklimine sahip bölgelerdeki bitkilerde dağılım göstermektedir ve tropik bölgelerde ise az sayıda tür bulunmaktadır. Afitlerin sahip olduğu bir üreme özelliği olan döngüsel parthenogenesis 1lıman bölgelerdeki kısa ömürlü bitkilerden faydalanmanın en başarılı yollarından biri olarak görülmektedir. Diğer taraftan Dixon (1987) tropik ormanlardaki geniş faunal çeşitliliğin konukçusuna spesifik olan ve kısa hayat döngüsüne sahip afitlerin çeşitliliğini azalttı̆̆ını ileri sürmektedir. Bunun sonucunda ülkemizin de içerisinde bulunduğu 1lıman iklime sahip bölgede afitlerin çeşitliliği daha yüksek seviyelere ulaşmaktadır. Ayrıca, afitlerin \%1'den az kısmı yüksek derecede polifag olarak adlandırılmasına rağmen konukçu bitki tercihleri nedeniyle en yıkıcı tarımsal zararlılar arasında yer almaktadır. Polifag afit türlerinin en bilinenlerinden olan Aphis gossypii Glover 116 bitki familyası içerisindeki 912 konukçu bitki üzerinde beslenmektedir (İnaizumi, 1980).

Avrupa ve Asya kıtaları arasında bir bağlantı noktası konumunda olan ülkemiz iklim ve topografik koşullarındaki çeşitlilikten dolayı oldukça zengin flora ve faunaya ev sahipliği yapmaktadır. Ülkemiz florası \%32'si endemik olmak üzere yaklaşık 12.000 bitki türünü içermektedir (Güner ve ark., 2012). Ayrıca ülkemiz fauna çeşitliliği de yaklaşık 80.000 tür ile temsil edilmektedir (Demirsoy, 2002). Ülkemiz faunası içerisinde afitler son yapılan kayıtlarla birlikte 541 tür ve 14 alltüre ulaşmıştır (Kök ve Kasap, 2019). Ülkemizin Güney Marmara Bölgesinde yer alan Çanakkale ili hem iki kıta arasındaki bağlantıyı sağlayan boğazı hem de sahip olduğu Akdeniz iklimi ile birlikte Kaz Dağları, Biga ve Gelibolu Yarımadaları gibi endemik tür oranı yüksek bölgeler sayesinde zengin floral ve faunal çeşitliliğe ev sahipliği yapmaktadır. Sadece Kaz Dağları Milli Parkı içerisinde 68 tanesi endemik olmak üzere 800'den fazla bitki türü bulunmaktadır (Özhatay ve Özhatay, 2005). Çanakkale ilinde Kök ve ark. (2016) ve Kök ve Kasap (2019) tarafından yürütülen çalışmalar sonucunda 45 bitki familyasında bulunan 133 konukçu bitki üzerinde Aphididae familyasından 40 cinse bağlı toplamda 85 afit türü tespit edilmiştir. Ayrıca yürütülen bu çalışmalarda tespit edilen Ajuga orientalis L. (Lamiaceae), Cynoglossum creticum Mill. (Boraginaceae), Helianthus annuus L. (Asteraceae), Pimpinella saxifraga L. (Apiaceae) ve Tragopogon porrifolius L. (Asteraceae) bitkileri afitler için Türkiye'de yeni konukçu bitki kayıtları olarak tespit edilmiştir. Bu sonuçlar Çanakkale ilinin hem afit hem de konukçu bitkilerinin çeşitliliği açısından zengin bir potansiyele sahip olduğunu göstermektedir.

$\mathrm{Bu}$ çalışmada Çanakkale ilinde yapılan örneklemeler sonucunda afitler ile bulaşık olduğu tespit edilen Capsella rubella Reut. (Brassicaceae) bitkisinin önemli afit türlerinden, Aphis craccivora Koch ve Brevicoryne brassicae (Linnaeus) için ülkemizde yeni konukçu bitki kaydı verilmiştir.

\section{Materyal ve Yöntem}

Bu çalışmada tespit edilen A. craccivora ve B. brassicae afit türlerine ait örneklemeler 2017 yılında Çanakkale il merkezine bağlı Taşlıtarla köyünde tespit edilen C. rubella konukçu bitkisi üzerinden yapılmıştır. Afit örneklemeleri teşhis işlemlerinin sağlıklı yapılabilmesi için üzerinde yeterli miktarda nimf ve ergin afitler bulunan konukçu bitkilerden arazi şartlarında doğrudan yapılmıştır. Üzerinde yeterli miktarda ergin birey bulunmayan konukçu bitkiler laboratuvara getirilerek $25 \pm 2{ }^{\circ} \mathrm{C}$, $\% 65 \pm 10$ orantılı nem ve 16:8 1şılklandırma süresine ayarlanmış iklim odasında ergin afitlerin elde edilebilmesi amacıyla kültüre alınmıştır. Yeterli sayıda nimf ve kanatlı-kanatsız ergin afit bireyleri içerisinde $\% 70$ oranında ethanol bulunan eppendorf tüpleri içerisine yumuşak bir firça kullanılarak aktarılmıştır. İçerisine afit bireylerinin koyulduğu eppendorf tüplerine kod numaraları yazılmış ve etiketleme işlemi gerçekleştirilmiştir. Bu kod numaraları oluşturulan arazi kayıt defterlerine yazılarak teşhislerde kullanılmak üzere ilgili kısımlara örnekleme yeri, tarih, konukçu bitki ve koordinatlar gibi bilgiler eklenmiştir.

Teşhisleri yapılmak üzere laboratuvara getirilen afit örnekleri öncelikle morfolojik teşhis karakterlerinin ortaya çıkarılması amacıyla temizleme işlemine tabi tutulmuş ve ardından preparasyon yapılmıştır. Bu amaçla Hille Ris Lambers (1950)'in önerdiği yöntem kullanılmıştır. Preparasyonu yapılan afit türlerinin teşhisleri morfolojik karakterlere göre Blackman \& Eastop (2006; 2019)'daki 
teşhis anahtarları kullanılarak yapılmıştır. Bu amaç doğrultusunda LEICA DM2500 mikroskop ile bağlı MC170 model HD kamera ve LAS 4.1 versiyon paket program kullanılarak afit türlerinin morfolojik karakterlerinin ölçümleri, farklı vücut kısımlarının birbirine oranı ve kıllanma durumları gibi özellikleri incelenmiştir. Teşhis edilen afit türlerinin güncel bilimsel isimleri ve taksonomik statüleri Favret (2019)'e göre düzenlenmiştir. Bu çalışmada tespit edilen afit türlerinin teşhisleri birinci yazar tarafından yapılmıştır. Konukçu bitkiler teşhisinin yapılabilmesi amacıyla sökülerek laboratuvara getirilmiş ve herbaryumu yapılarak teşhis işlemi gerçekleştirilmiştir. Konukçu bitkilerin teşhis işlemleri üçüncü yazar tarafından gerçekleştirilmiştir.

Teşhisi tamamlanan afit türlerinin kalıcı preparatları Çanakkale Onsekiz Mart Üniversitesi, Ziraat Fakültesi, Bitki Koruma Bölümünde saklanmaktadır.

\section{Bulgular ve Tartışma}

$\mathrm{Bu}$ çalışma kapsamında Çanakkale ilinde bulunan merkeze bağlı Taşlıtarla köyünde $\left(40^{\circ} 04^{\prime} 60.0^{\prime \prime} \mathrm{N} 26^{\circ} 24^{\prime} 57.9^{\prime \prime} \mathrm{E}\right)$ genellikle tarım alanlarının etrafinda 24.05.2017 tarihinde yapılan örneklemeler sonucunda önemli afit türlerinden olan A. craccivora ve B. brassicae için Brassicaceae familyasında yer alan $C$. rubella bitkisi Türkiye'de yeni konukçu bitki kaydı olarak tespit edilmiştir. Bulaşık bitkilerin örneklemeleri sırasında iki afit türünün de C. rubella üzerinde koloniler halinde karışık olarak bulunduğu ve $A$. craccivora'nın genellikle bitkinin sürgün uçlarında ve yaprağın gövdeye bağlandığı sap kısmında, $B$. brassicae'nin ise bitkinin daha çok gövde kısmı üzerinde koloni oluşturduğu belirlenmiştir. Bitki üzerinde bulunan $A$. craccivora kolonilerinde kanatlı ve kanatsız bireylerin bir arada olduğu belirlenirken, B. brassicae kolonilerde de kanatlı ve kanatsız bireylerin olduğu tespit edilmiştir. Örneklemesi yapılan afitler ile bulaşık bitkiler üzerinde yapılan gözlemlerde herhangi bir doğal düşmana rastlanmamıştır.

$\mathrm{Bu}$ çalışmada toplanan örneklerden teşhislerin gerçekleştirilmesi amacı ile A. craccivora'ya ait 1 kanatlı $q$ ve 1 kanatsız $q$ birey incelenmiştir (Şekil 1). A. craccivora genellikle parlak siyahıms1 bir vücut rengine sahip olup ergin öncesi bireylerin üzeri tozlumsu bir mum tabakası ile kaplıdır. Fabaceae familyası başta olmak üzere birçok konukçu bitkinin genç sürgünlerinde koloni oluşturmaktadır. Dünya'da baklagillerin en önemli zararlılarından biri olarak kabul edilmektedir (Blackman and Eastop, 2000). Bu afit türünün ülkemizdeki ilk kaydı Robinia pseudoacaciae L. üzerinden 1939 yılında yapılmıştır (Bodenheimer and Swirski, 1957). A. craccivora ülkemizin de yer aldığ 1 Palearktik bölgede yapılan çalışmalarda farklı familyalardan yaklaşık 800 konukçu bitki üzerinde kayıt edilmiştir (Holman, 2009). Şimdiye kadar ülkemizin farklı bölgelerinde yürütülen çalışmalarda ise Acacia sp., A. dealbata, Acantholimon sp., Acer negundo, Alhagi sp., A. camelorum, Alianthus glandulosa, Allium cepa, Alchemilla vulgaris, Amaranthus albus, A. retroflexus, Anagallis sp., Anchusa sp., A. azurea, Anthemis sp., Arachis hypogaea, Asparagus sp., Astrodancus sp., Bougainvillea spectablis, Brassica oleracea, Bromus japonicus, B. sterilis, Callendula sp., Calluna sp., C. vulgaris, Camellia japonica, Capsella bursa pastoris, Capsicum annum, Lepidium draba (=Cardaria draba), Catalpa bignonioides, Centaurea iberica, Ceratonia siluqua, Cercis siliquastrum, Cheiranthus cheiri, Chenopodium album, Cicer arietinum, Cichorium intybus, Cirsium sp., Citrullus vulgaris, Citrus aurantium, C. limon, C. nobilis, C. paradisi C. sinensis, Colutea sp., C. arborescens, Convolvulus arvensis, Crepis foetida, Cucumis melo, Cydonia oblonga, Dipsacus laciniatus, Dolichos sp., Dorycnium graecum, Erodium cicutarium, Eucalyptus sp., Euphorbia sp., Ficus lyrata, F. nituda, Fraxinus ornus, Galega officinalis, Galium aparine, Gleditschia triacanthos, Glycyrrhiza glabra, Gossypium herbaceum, G. hirsutum, Gypsophila sp., Hedera helix, Heracleum sp., Hibiscus esculentus, H. syriacus, Jacaranda mimosifolia, Lactuca sp., Lens esculentum, Lycopersicon esculentum, Malus domestica, Medicago sativa, Melilotus sp., M. officinalis, Mespilus germenica, Onobrychis sp., O. viciifolia, Parkinsonia aculeata, Petunia hybrida, Phaseolus vulgaris, Platanus orientalis, Polygala sp., Portulaca oleracea, Prunus amygdalus, P. armeniaca, P. domestica, P. persica, P. serrulata, P. spinosa, Pyrus communis, Ribes rubrum, Robinia pseudoacacia, Rosa sp., Rubus sp., Rumex alpinus, R. crispus, R. patienta, Salix sp., Salvia sp., Sanguisorba minor, Senecio vulgaris, Scaligeria sp. Scorzonera cana, Silene sp. Solanum melongena, S. nigrum, Sonchus sp., Spartium junceum, Spiraea $x$ vanhouttei, Syringia sp., Taraxacum sp., T. officinale, Tribulus terrestris, Trifolium sp., T. fragiferum, T. stellatum, Trigonella sp., T. monantha subsp. noeouana, Tripleurospermum decipiens, Ulex auauropaeus, Urtica urens, Verbascum sp., Viburnum opulus, V. 
tinus, Vicia sp., V. sativa, V. angustifolia, V. cypria, V. faba, V. grandiflora var. grandiflora, V. villosa, Vigna sinensis, Vitex angus-castus ve Wisteria sp. bitkileri üzerinde kayit edilmiştir (Düzgüneş ve Tuatay, 1956; Bodenheimer ve Swirski, 1957; Tuatay ve Remaudiere, 1964; Tuatay ve ark., 1967; Giray, 1974; Çanakçığlu, 1975; Düzgüneş ve ark., 1982; Tuatay, 1993, Toros ve ark., 2002; Ölmez Bayhan ve ark., 2003; Özdemir, 2004; Altay ve Uysal, 2005; Aslan ve Uygun, 2005; Ayyıldız ve Atlıhan, 2006; Çıraklı ve ark., 2008; Eser ve ark., 2008; Narmanlığlu ve Güçlü, 2008; Akyıldırım, 2010; Tepecik, 2010; Güleç 2011; Akyürek ve ark., 2012; Kılıç ve Yoldaş, 2012; Akyürek, 2013; Ülgentürk ve ark., 2013; Saraç, 2014; Çalışkan, 2015; Yıldırım ve Eroğlu, 2015; Kök ve ark., 2016; Kuloğlu ve Özder, 2017; Öztürk ve Muştu, 2017; Tıraş ve Yaşar, 2017; Bayındır Erol ve ark., 2018; Kök ve Kasap, 2019).

$\mathrm{Bu}$ çalışmada toplanan örneklerin teşhis edilmesi sonucunda $C$. rubella üzerinde tespit edilen diğer bir tür $B$. brassicae'nin 5 kanatsız 1 kanatlı $q$ bireyi morfolojik olarak incelenmiştir (Şekil 1). $B$. brassicae vücut genellikle grimsi yeşil veya donuk yeşil renkte, baş kısmı koyu ve toraks ve abdomen segmentlerinde koyu lekeler bulunmaktadır. Vücut yoğun bir şekilde grimsi beyaz mum tabakası ile kaplıdır. B. brassicae türü Brassicaceae familyasına ait birçok konukçu bitkiyi tercih etmektedir ve bu familyaya ait tarımsal üretimi yapılan bitkilerin en önemli zararlılarından biridir (Blackman ve Eastop, 2000). Bu afit türünün ülkemizdeki ilk kaydı Brassica oleracea L. üzerinden Düzgüneş ve Tuatay (1956) tarafından yapılmıştır. B. brassica ülkemizin de yer aldığı Palearktik bölgede yapılan çalışmalarda farklı familyalardan yaklaşık 200 konukçu bitki üzerinde kayıt edilmiştir. Şimdiye kadar ülkemizin farklı bölgelerinde yürütülen çalışmalarda ise Brassica sp., B. acephala, B. nigra, B. oleracea, B. napus, Bunias orientalis, Capsella bursa-pastoris, Cardaria draba, Crambe sp., Diplotaxis tenuifolia, Hirschfeldia incana, Isatis sp., I. floribunda, I. glauca, Plantago lanceolata, Raphanus raphanistrum, $R$. sativus, Scolymus hispanicus, Sisymbrium sp., S. altissimum ve Sinapis arvensis bitkileri üzerinde kayıt edilmiştir (Bodenheimer ve Swirski 1957; Toros ve ark., 2002; Özdemir, 2004; Altay ve Uysal, 2005; Aslan ve Uygun, 2005; Eser ve ark., 2008; Akyıldırım, 2010; Güleç, 2011; Akyürek ve ark., 2012; Akyürek, 2013; Bayındır Erol ve ark. 2018; Kök ve Kasap, 2019).

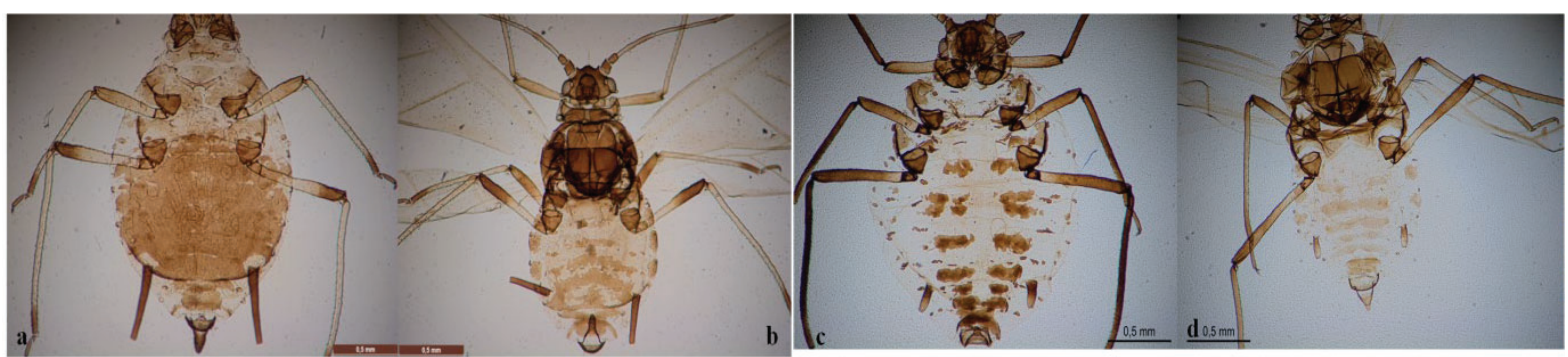

Şekil 1. Aphis craccivora'nın a- kanatsız dişi vücut görünümü, b- kanatlı dişi vücut görünümü ve Brevicoryne brassicae'nin c- kanatsız dişi vücut görünümü, d- kanatlı dişi vücut görünümü

Afitler hayat döngüleri esnasında konukçu bitkilerine sıkı bir bağlılık göstermesinden dolayı hem bu zararlıların morfolojik olarak teşhislerinin doğru yapılması hem de biyolojilerinin daha iyi anlaşılarak oluşturacağı zararlar için mücadele planlamalarının yapılmasında konukçu bitkilerinin bilinmesi oldukça önemlidir. Ülkemiz sahip olduğu yaklaşık 12.000 bitki türü ile başta afitler olmak üzere diğer birçok böcek türüne konukçuluk etmesi bakımından oldukça zengin potansiyele sahiptir. Hem ülkemizde hem de Çanakkale ilinde yürütülen daha önceki çalışmalar afit faunasının farklı konukçu bitkiler üzerinde ve farklı bölgelerde kapsamlı bir şekilde araştırıldığında artış gösterme potansiyelini ortaya koymaktadır. Afitler ve konukçu bitkiler üzerine farklı çalışmalar yürütülmesine rağmen bu konudaki en kapsamlı çalışma ülkemizin de yer aldığı Palearktik Bölgede Holman (2009) tarafindan gerçekleştirilmiştir. Bu çalışmada 3.706 afit türünün konukçusu olarak 248 bitki familyasından 11.131 konukçu bitki türü listelenmiştir. Bu sonuçlar da konukçu bitkilerin afitlerin yaşamları üzerindeki etkisinin önemini ortaya koymaktadır. 


\section{Sonuç ve Öneriler}

Ülkemizde 1900'lü yılların başından itibaren başlayan afitler ile ilgili faunal çalışmalar özellikle 2000'li yıllardan itibaren daha hızlı bir atış göstermiştir. Farklı bölgelerde yürütülen çalışmalar sonucunda afit türleri ile birlikte üzerinde bulunduğu farklı familyalara ait sayısız konukçu bitki de tespit edilmiştir. Ülkemizde tespit edilen tüm afit türlerinin listelendiği çeşitli yıllarda yapılan çalışmalar olmasına rağmen afitlerin konukçu bitkilerinin tümüyle listelendiği şimdiye kadar yapılmış ulusal düzeyde herhangi bir kapsamlı çalışma bulunmamaktadır. Bu çalışmada ülkemizde hem tarım alanlarında hem de tarımdışı alanlarda en çok rastlanan afit türlerinin başında gelen $A$. craccivora ve B. brassicae için C. rubella konukçu bitkisinin kaydı ülkemizde ilk kez verilmiştir. Ayrıca ülkemizde şimdiye kadar yürütülen bütün çalışmalarda bu afit türlerinin tespit edildiği konukçu bitkiler de verilmiştir. Yürütülen çalışmalar sonucunda yeni afit türlerinin eklenerek faunanın arttırılmasının yanı sıra yeni konukçu bitki kayıtlarının sağlanması için yapılacak kapsamlı bölgesel çalışmaların hem Çanakkale ili hem de ülkemiz adına önemini ortaya koymaktadır. Bu bağlamda ülkemizde afitler ve tercih ettikleri konukçu bitki türlerini net olarak ortaya koyacak ve rehber görevi üstlenecek ulusal düzeyde kataloglama çalışmalarına ihtiyaç duyulmaktadır.

Not: Bu makale sorumlu yazarın Doktora tezinin bir kısmından hazırlanmıştır.

\section{Kaynaklar}

Akyıldırım, H., 2010. İstanbul ili Büyükada ilçesi afit (Hemiptera: aphidoidea) faunasının belirlenmesi. Niğde Üniversitesi, Fen Bilimleri Enstitüsü, Biyoloji Anabilim Dalı, Doktora tezi. 101 s.

Akyürek, B., 2013. Samsun ili Aphididae (Hemıptera: Aphidoidea) familyası turlerinin taksonomik yönden incelenmes.. Ondokuz Mayıs Üniversitesi, Fen Bilimleri Enstitüsü, Bitki Koruma Anabilim Dalı, Doktora Tezi. $378 \mathrm{~s}$.

Akyürek, B., Zeybekoğlu, Ü., Görür, G., 2012. Ondokuz Mayıs Üniversitesi Kurupelit Yerleşkesi (Samsun)'nin yaprakbiti (Hemiptera: Aphididae) türleri ve konukçu bitkileri. Türkiye Entomoloji Bülteni. 2(2): 91108.

Altay, H., Uysal, M., 2005. Selçuk Üniversitesi Alaeddin Keykubat kampüs alanında bulunan yaprakbiti (Homoptera: Aphidoidea) türleri. S.Ü. Ziraat Fakültesi Dergisi. 19(37): 92-99.

Aslan, M.M., Uygun, N., 2005. Aphids (Homoptera: Aphididae) of Kahramanmaraş province, Turkey. Turkish Journal of Zoology. $29:$ 201-209.

Ayyıldız, Y., Atlıhan, R., 2006. Balıkesir ili sebze alanlarında görülen yaprakbiti türleri ve doğal düşmanları. Yüzüncü Yıl Üniversitesi Ziraat Fakültesi Tarım Bilimleri Dergisi 16(1): 1-5.

Bayındır Erol, A., Arzuman, Ş., Özdemir, I., Karaca, İ., 2018. Isparta ili kampüs alanları içerisinde belirlenen yaprakbiti (Hemiptera: Aphididae) türleri. Süleyman Demirel Üniversitesi Fen Bilimleri Enstitüsü Dergisi. 22(2): 1045-1053.

Blackman, R.L., Eastop V.F., 2000. Aphid's on The World's Crops: An Identification and Information Guide (2nd ed.). John Wiley and Sons, 476 p., Chichester, England.

Blackman, R.L., Eastop, V.F. 2019. Aphids on the World's Plants an Online Identification and Information Guide, (Web page: www.aphidsonworldsplants.info) (Online Erişim: September 2019).

Blackman, R.L., Eastop, V.F., 2006. Aphids on the World's Herbaceous Plants and Shrubs. John Wiley \& Sons Ltd., 1439 p., Naturel History Museum, London.

Bodenheimer, F.S., Swirski, E., 1957. The Aphidoidea of the Middle East. Weizmann Science Press of Israel, 378 p., Jerusalem.

Çalışkan, A.F., 2015. Adana ili park ve peyzaj alanlarında zararlı olan Sternorrhyncha (Hemiptera) (Aleyrodidae, Coccoidea, Aphididae) türlerinin saptanması. Çukurova Üniversitesi Fen Bilimleri Enstitüsü Bitki Koruma Anabilim Dalı, Doktora Tezi. 315 s.

Çanakçıoğlu, H., 1975. The Aphidoidea of Turkey. Ist. Uni. Fac. Forest. Publication, 309 p., İstanbul.

Çıraklı, A., Görür, G., Mustafa, I., 2008. Denizli il merkezinde belirlenen afit (Hemıtera: Aphıdıdae) türleri. Selçuk Üniversitesi Ziraat Fakültesi Dergisi. 22(44): 12-18.

Demirsoy, A., 2002. Genel ve Türkiye Zoocoğrafyası, third ed. Meteksan, Ankara.

Dixon, A.F.G., 1987. The way of life of aphids: host specificity, speciation and distribution. In: Minks AK, Harrewijn P, editors. Aphids, p. 197-207. Elsevier, New York.

Dixon, A.F.G., 1998. Aphid ecology - an optimization approach. Kluwer Academic Pub, Norwell.

Düzgüneş, Z., Toros, S., Kılınçer, N., Kovanc1, B., 1982. Ankara ilinde bulunan Aphidoidea türlerinin parazit ve predatörleri. Tar. Orm. Bak. Zirai Müc. Zirai Karan. Gnl. Müd., 251 s., Ankara. 
Düzgüneş, Z., Tuatay N., 1956. Türkiye Aphid'leri. Ankara Zirai Mücadele Enstitüsü Müdürlüğü Yayınları Sayı 4. $63 \mathrm{~s}$.

Eser, S.İ., Görür, G., Tepecik, İ., Akyıldırım, H., 2008. Aphid (Hemiptera: Aphidoiea) species of the Urla district of İzmir region. Journal of Applied Biological Sciences. 3(1): 92-95.

Favret, C., 2019. Aphid species file (Version 5.0/5.0). (Web page: aphid.speciesfile.org) (Online Erişim: September 2019).

Giray, H., 1974. İzmir ili çevresinde Aphididae (Homoptera) familyası türlerine ait ilk liste ile bunların konukçu ve zarar şekilleri hakkında notlar. Ege Üniversitesi Ziraat Fakültesi Dergisi. 11(1): 39-69.

Güleç, G., 2011. Antalya şehri park alanlarında Aphidoidea (Hemiptera) türlerinin saptanması ve doğal düşmanlarının belirlenmesi. Ankara Üniversitesi Fen Bilimleri Enstitüsü Bitki Koruma Anabilim Dalı, Doktora Tezi. $325 \mathrm{~s}$.

Güner, A., Aslan, S., Ekim, T., Vural, M., Babaç, M.T., 2012. Türkiye Bitkileri Listesi (Damarli Bitkiler). Nezahat Gökyigit Botanik Bahçesi ve Flora Araştirmalari Dernegi Yayini. Istanbul

Hille Ris Lambers, D., 1950. On mounting Aphids and other soft skinned insects. Entomologische Berichten, XIII: 55-58.

Hille Ris Lambers, D., 1979. Aphids as Botanists? Symbolae Botanicae Uppsalienses. 114-119 pp.

Holman, J., 2009. Host Plant Catalog of Aphids, Palaearctic Region. Springer, Branisovska, ISBN: 978-1-40208285-6, $1216 \mathrm{p}$.

Inaizumi, M., 1980. Studies on the life cycle and polymorphism of Aphis gossypii Glover (Homoptera, Aphididae). Special Bulletin of the College of Agriculture, Utsunomiya University, 132 p., Tochigi.

Kılıç, T., Yoldaş, Z., 2012. İzmir ilinde taze soğan tarlalarında saptanan böcek türleri. Türkiye Entomoloji Dergisi, 36(2): 287-298.

Kök, Ş., Kasap, İ., 2019. Aphid (Hemiptera: Aphididae) species of the South Marmara Region of Turkey including the first record of Dysaphis radicola meridialis Shaposhnikov, 1964 for the aphid fauna of Turkey. Turkish Journal of Entomology. 43(1): 63-78.

Kök, Ş., Kasap, İ., Özdemir, I., 2016. Aphid (Hemiptera: Aphididae) species determined in Çanakkale Province with a new record for the aphid fauna of Turkey. Türkiye Entomoloji Dergisi. 40(4): 397-412.

Kuloğlu, I., Özder, N., 2017. Aphids (Hemiptera: Aphididae) on ornamental plants from Yalova Province, Turkey. ÇOMÜ Ziraat Fakültesi Dergisi. 5(2): 69-72.

Narmanlığlu, K., Güçlü, Ş., 2008. İspir (Erzurum) İlçesi’nde meyve ağaçlarında bulunan yaprakbiti türleri (Homoptera: Aphididae) ve doğal düşmanları. Atatürk Üniversitesi Ziraat Fakültesi Dergisi. 39(2): 225229.

Ölmez Bayhan, S., Ulusoy, M.R., Toros, S., 2003. Determination of Aphididae (Homoptera) fauna of Diyarbakir Province of Turkey. Türkiye Entomoloji Dergisi. 27(4): 253-268.

Özdemir, I., 2004. Ankara ilinde otsu bitkilerde Aphidoidea türleri üzerinde taksonomik araştırmalar. Ankara Üniversitesi Fen Bilimleri Enstitüsü Bitki koruma Anabilim Dalı, Doktora Tezi, 189 s.

Özhatay, N., Özhatay, E., 2005. Kazdağı, 73-76. In: Türkiye’nin 122 Önemli Bitki Alanı (Eds. N. Özhatay, A. Byfield \& S. Atay), Türkiye Doğal Hayatı Koruma Vakfı, İstanbul, 476 s.

Öztürk, D.Ö., Muştu, M., 2017. Kayseri’nin merkez ilçelerinde süs bitkilerinde bulunan yaprakbiti (Hemiptera: Aphididae) türleri. Türkiye Entomoloji Bülteni. 7(4): 277-292.

Saraç, 2014. Antalya ili turunçgil bahçelerinde yaprakbiti türleri, avcı ve asalaklarının saptanması. Süleyman Demirel Üniversitesi Fen Bilimleri Enstitüsü Bitki Koruma Anabilim Dalı, Doktora Tezi. 73 s.

Tepecik, 2010. Karabük ilinin afit faunasının belirlenmesi. Niğde Üniversitesi Fen Bilimleri Enstitüsü Biyoloji Anabilim Dalı, Doktora Tezi. $128 \mathrm{~s}$.

Tıraş, Z., Yaşar, B., 2017. Antalya ilinde kesme çiçek seralarında bulunan zararlı böcek ve akar türleri. Süleyman Demirel Üniversitesi Fen Bilimleri Enstitüsü Dergisi. 21(1):1-8.

Toros, S., Uygun, N., Ulusoy, R., Satar, S., Özdemir, I., 2002. Doğu Akdeniz Bölgesi Aphidoidea Türleri. Tarım ve Köyişleri Bakanlığı Tarımsal Araştırmalar Genel Müdürlüğü, 108 s. Ankara.

Tuatay, N., 1993. Aphids of Turkey (Homoptera: Aphididae) IV. Aphidinae: Macrosiphini Part IV. Bull. Plant. Pro. 33(1-2): 83-105.

Tuatay, N., Gül, S., Demirtola, A., Kalkandelen, A., Çağatay, N., 1967. Nebat Koruma Müzesi Böcek Kataloğu (1961-1966), T. C. Tar. Bak. Zir. Müc. Zir. Kar. Gn. Md. Yayınları, Mesleki Kitaplar Serisi. 119 s., Ayyıldız Matbaası, Ankara.

Tuatay, N., Remaudière, G., 1964. Première Contribution au Catalogue des Aphididae (Hom.) de la Turquie. Rev. Path. Vég. Entomol. Agr. France. 43 (4): 243- 278.

Ülgentürk, S., Özdemir, I., Kozár, F., Kaydan, M.B., Dostbil, Ö., Sarıbaşak, H., Civelek, H.S, 2013. Honeydew producing insect species in forest areas in Western Turkey. Türkiye Entomoloji Bülteni. 3(4): 125-133.

Yıldırım, E., Eroğlu, Z., 2015. Atatürk Üniversitesi (Erzurum) Yerleşkesinde odunsu bitkilerde bulunan zararlı böcek türleri. Atatürk Üniversitesi Ziraat Fakültesi Dergisi. 46(1): 29-37. 